\title{
Pengaruh Pengantar Pasien, Kondisi Pasien, Dan Beban Kerja Tenaga Kesehatan IGD Terhadap Waktu Tanggap Di IGD RSIA Bunda Aliyah Jakarta Tahun 2020
}

\author{
Erwin Darma, Cicilia Windiyaningsih, Syarief Hasan Lutfie \\ Program Studi Magister Administrasi Rumah Sakit \\ Program Pascasarjana Universitas Respati Indonesia \\ erwinkrs@gmail.com
}

\begin{abstract}
Abstrak
Response Time merupakan waktu antara dari permulaan suatu permintaan ditanggapi, waktu tanggap yang baik yaitu 5 menit akan berdampak buruk bagi kualitas hidup pasien. Dimana faktor eksternal dapat mempengaruhi response time perawat dan dokter diantaranya pengantar pasien, kondisi pasien, dan beban kerja tenaga kesehatan. Tujuan penelitian untuk mengetahui apakah ada hubungan faktorfaktor tadi dengan response time tenaga kesehatan dalam penanganan pasien gawat darurat. Sampel diambil dengan teknik pengambilan total sampling yaitu 30 sampel. Desain penelitian yang digunakan adalah survey analitik dengan pendekatan cross sectional dan data dikumpulkan menggunakan lembar observasi langsung dan lembar kuesioner. Hasil penelitian uji statistic chi square didapatkan tidak terdapat pengaruh antara pengantar pasien terhadap waktu tanggap diperoleh nilai dengan taraf signifikansinya 0,260 (lebih besar dari 0,05), terdapat pengaruh antara kondisi pasien terhadap waktu tanggap diperoleh nilai dengan taraf signifikansinya $0,014(<0,05)$, terdapat pengaruh antara beban kerja tenaga kesehatan IGD terhadap waktu tanggap diperoleh nilai dengan taraf signifikansinya $0,029(<0,05)$ Saran: Diharapkan bagi pihak mutu rumah sakit selalu memantau, mengevaluasi waktu tanggap pelayanan pasien terutama yang true emergency di instalasi gawat darurat supaya waktu tanggapnya selalu sesuai standar pelayanan minimal baik standar nasional maupun internasional.
\end{abstract}

Kata Kunci: waktu tanggap, response time, pengantar pasien, kondisi pasien, dan beban kerja tenaga kesehatan.

\begin{abstract}
Response Time is the time between when a request is responded to, a good response time of 5 minutes will have a negative impact on the patient's quality of life. Where external factors can affect the response time of nurses and doctors, including patient companion, patient condition, and workload of health workers. The aim of the study was to determine whether there was a relationship between these factors and the response time of health workers in handling emergency patients. Samples were taken by total sampling technique, namely 30 samples. The research design used was an analytic survey with a cross sectional approach and the data were collected using direct observation sheets and questionnaire sheets. The results of the chi square statistical test showed that there was no influence between the patient's companion to the response time, the value was obtained with a significance level of 0.260 (greater than 0.05), there was an influence between the patient's condition on the response time, the value was obtained with a significance level of $0.014(<0.05)$, there was an influence between the workload of health workers on the response time, the value is obtained with a significance level of 0.029 (<0.05). always in accordance with the minimum service standards both national and international standard
\end{abstract}

http://ejournal.urindo.ac.id/index.php/MARSI 
Keywords: response time, patient companion, patient condition, and workload of health workers

\section{PENDAHULUAN}

Tantangan global bagi tenaga kesehatan sangat terkait dengan berlakunya AFTA 2015 dalam mempersiapkan tenaga kesehatan yang berkualitas di bidang kesehatan, antara lain tentang pelayanan rumah sakit, pelayanan dokter, pelayanan lain termasuk pelayanan keperawatan. Rumah sakit merupakan suatu institusi perawatan kesehatan profesional yang pelayanannya menyiapkan tenaga dokter, perawat, dan tenaga ahli kesehatan lainnya.

Dalam era global ini semua penyedia layanan kesehatan yang ada termasuk persaingan perawat dan dokter tidak hanya datang dari dalam negeri, tetapi juga datang dari pesaing negara Asia Tenggara lainnya. Berbagai keterampilan yang wajib dikuasai perawat dan dokter adalah keterampilan intelektual, teknikal, dan interpersonal. Keterampilan intelektual meliputi semua dasar ilmu tentang keperawatan dan kedokteran. Keterampilan teknikal meliputi semua tindakan teknis keperawatan dan kedoktern. Keterampian interpersonal adalah ciri khas kepribadian perawat dn dokter yang harus dimunculkan dalam pelayanan kesehatan.

Rumah sakit di Indonesia harus mampu bersaing dengan rumah sakit di seluruh Asia Tenggara. Rumah sakit dibedakan dari institusi kesehatan lain dari kemampuan tenaga kesehatannya memberikan diagnosa dan perawatan medis secara menyeluruh kepada pasien. Salah satu dari pelayanan di rumah sakit adalah Instalasi Gawat Darurat (IGD).

IGD adalah salah satu unit pelayanan di rumah sakit yang menyediakan penanganan awal (bagi pasien yang datang langsung ke rumah sakit) atau lanjutan (bagi pasien rujukan dari fasilitas pelayanan kesehatan lain), menderita sakit ataupun cedera yang dapat mengancam kelangsungan hidupnya dan berfungsi menerima, menstabilkan dan mengatur pasien yang membutuhkan penanganan kegawatdaruratan segera, baik dalam kondisi sehari-hari maupun bencana.

Instalasi Gawat Darurat atau IGD adalah salah satu unit terpenting dari bagian pelayanan kesehatan di rumah sakit yang memberikan pelayanan pada pasien gawat darurat. Tenaga kesehatan di IGD memegang peranan yang amat penting dan mampu menentukan kualitas dan hasil akhir dari sebuah layanan kesehatan yang dilakukan, oleh sebab itu IGD juga dituntut untuk mampu bekerja sama dengan unit terkait lainnya dalam menghadirkan pelayanan kesehatan yang ideal. Tercapainya pelayanan kesehatan pada kasus gawat darurat yang optimal melalui pelayanan IGD yang cepat, tepat dan profesional diharapkan mampu mencegah resiko kecacatan dan kematian penderita.

Instalasi Gawat Darurat menyediakan layanan gawat darurat selalu buka 24 jam dan menjadi unit terdepan dari bagian pelayanan rumah sakit yang memberikan pelayanan pada pasien gawat darurat (emergency) dan false emergency bekerja sama dengan unit terkait dengan tujuan pemeriksaan, diagnosis, pengobatan, pengamatan, dan berbagai layanan medis lain yang dilakukan. Pelayanan gawat darurat sangat penting khususnya untuk pengecekan berbagai penyakit dan kemungkinan hidup pasien berdasarkan pedoman triase. Dengan triase ini kita dapat memberikan pelayanan yang lebih maksimal.

Pemberian pelayanan yang tepat dan cepat merupakan standar pelayanan yang dapat digunakan sebagai acuan pelayanan gawat darurat oleh tenaga medis dan pihak rumah sakit, untuk mendukung terwujudnya pelayanan yang berkualitas, efektif dan efisien. Kepmenkes 856 tahun 2009 mengatur secara tertulis standarisasi pelayanan instalasi gawat darurat di rumah sakit menurut kelas RS, semakin besar kelas RS maka semakin lengkap sumber daya manusia dan peralatannya karena kasus pasien yang diterima semakin kompleks. 
Pelayanan di instalasi gawat darurat tidak menggunakan sistem antrian tapi dengan sistem triase. Triase IGD adalah proses penentuan atau seleksi pasien yang diprioritaskan untuk mendapat penanganan terlebih dahulu di ruang Instalasi Gawat Darurat (IGD) di rumah sakit. Proses penentuan ini dilakukan untuk mendapatkan urutan penanganan sesuai tingkat kegawatdaruratan pasien, seperti kondisi cedera ringan, cedera berat yang bisa mengancam nyawa dalam hitungan menit atau sudah meninggal.

Semakin lama pelayanan di instalasi gawat darurat akan memperparah kondisi pasien, memperburuk kondisi pasien sehingga terjadi peningkatan mortalitas dan kecacatan lebih lanjut. Semakin parahnya kondisi pasien maka akan meningkatkan biaya (cost) yang akan ditanggung oleh pasien.

Lama waktu tanggap di IGD (response time) adalah waktu dari pasien datang ke IGD sampai pasien ditangani dokter atau perawat. Lama waktu tanggap pasien di IGD merupakan salah satu indikator kualitas pelayanan di instalasi gawat darurat. Menurut standar yang berlaku di Indonesia yaitu standar pelayanan waktu tangggap pasien di instalasi gawat darurat adalah $\leq 5$ menit (Kepmenkes 129 tahun 2008).

Waktu tanggap dapat dihitung dengan hitungan menit, namun waktu tanggap dapat dipengaruhi beberapa faktor yaitu: 1 ) jumlah tenaga yang tersedia di IGD, 2) sarana dan prasarana, 3) pendidikan, dan faktor lain yang mendukung. Dikatakan tepat waktu apabila waktu tanggap yang diperlukan dalam memberikan respon tidak melebihi waktu ratarata atau standar yang sudah di tentukan. Pelaksanaan waktu tanggap yang memadai di Indonesia masih memerlukan evaluasi lebih lanjut dan yang menjadi indikator keberhasilan waktu tanggap penderita gawat darurat adalah kecepatan dalam memberikan pertolongan kepada pasien dalam keadaan rutin sehari-hari maupun sewaktu bencana serta bantuan yang diberikan untuk menyelamatkan nyawa atau mencegah kecacatan. (Rima, 2015, Soetrisno, 2013 dan Yuliati, 2018).

http://ejournal.urindo.ac.id/index.php/MARSI
Waktu tanggap yang cepat dari petugas kesehatan di IGD sangat meringankan pasien maupun keluarga memang dapat meringankan biaya pengobatan, namun pelayanan kesehatan yang diberikan tenaga kesehatan kepada pasien haruslah sesuai dengan standar yang sudah ditentukan oleh kompetensi dan kemampuan tenaga medis agar dapat menjamin dalam memberikan pelayanan kegawatdaruratan yang cepat dan tepat. Hal ini dapat dicapai dengan meningkatkan serta melengkapi sarana, prasarana, sumber daya manusia dan manajemen rumahsakit/puskesmas sesuai standar. (Wilde, 2009 dan Soetrisno, 2013).

Keberhasilan tindakan dalam mengatasi kegawatdaruratan dapat dinilai dari: 1) Pelayanan pertama pada saat terjadi kegawatdaruratan dan dapat dikategorikan terlambat apabila tindakan yang di berikan kepada pasien > 5 menit, 2) Petugas IGD adalah petugas yang bekerja di IGD Rumah sakit yang telah dilatih Penanggulangan Penderita Gawat Darurat (PPGD), 3) Tindakan untuk menyelamatkan hidup pasien jiwa yang sedang gawat darurat. (Patricia, 2013).

Sementara itu, faktor- faktor yang dapat mempengaruhi waktu tanggap di IGD meliputi: 1) karakter pasien, 2) penempatan staf, 3) brangkar, rostul dan alat lainnya yang digunakan untuk memindahkan pasien ke ambulans atau tempat tidur) 4) petugas kesehatan, waktu ketibaan pasien, 5) pelaksanaan manajemen, 6) strategi pemeriksaan, 7) penanganan yang dipilih, 8) masa kerja, 9) pendidikan, 10) beban kerja (Jordiawan, 2015, Kemenkes, 2009 dan Munandar, 2012).

Pada pelayanan di IGD masih sering dijumpai waktu tanggap pasien yang lebih dari 5 menit. Berdasarkan hasil penelitian dari beberapa sumber referensi seperti jurnal dan telaah pustaka yang peneliti peroleh menunjukkan bahwa masih ditemukan waktu tanggap yang belum sesuai standar seperti hasil penelitian di RSUP Prof. DR. R.D. Kandou Manado, dimana sebesar $54 \%$ dari total jumlah 
pasien IGD dalam periode waktu waktu tanggapnya lebih dari 5 menit. Faktor yang menyebabkan waktu tanggap pasien lebih dari 5 menit disebabkan oleh proses administrasi yang tidak selesai, tenaga kesehatan yang tidak cukup, dan pasien yang tidak ada keluarga. (Oliviani, 2015).

Hasil penelitian lain juga menunjukkan beberapa faktor yang mempengaruhi waktu tanggap yaitu karakteristik pasien (Hannibal Pardede, 2000). Penelitian lain juga menunjukkan bahwa kondisi pasien yang gawat darurat mempunyai 5 kali lebih besar untuk waktu tanggap sesuai dengan standar dibandingkan dengan yang tidak gawat darurat. Kondisi pasien gawat darurat berkontribusi dalam waktu tanggap sebesar $13 \%$ (Ines Marianne Santoso, 2016).

Sementara penelitian lainnya menyebutkan bahwa tidak terdapat hubungan yang signifikan antara tingkat kegawatan pasien, keberadaan petugas yang bersiaga di triase, dan ketersediaan brankar (sarana prasarana IGD) dengan ketepatan waktu tanggap. Analisis hubungan antara keberadaan petugas dan ketepatan waktu tanggap tidak dapat dilakukan. (Nailatulah Fadhilah, 2013). Ada juga hubungan masa kerja perawat dan beban kerja perawat dengan waktu tanggap seperti penelitian yang dilakukan di IGD RS Grandmed Lubuk Pakam (Tati Murni Karo-karo, 2020).

Dengan mempelajari fenomena yang terjadi di lapangan, melakukan studi literatur dari hasil penelitian terkait waktu tanggap, dan mempelajari teori terkait dengan faktor-faktor yang mempengaruhi waktu tanggap di IGD rumah sakit, maka peneliti berpendapat bahwa waktu tanggap (response time) adalah faktor yang sangat penting dalam memberikan pelayanan kepada pasien di IGD rumah sakit.

Oleh sebab, maka peneliti tertarik untuk mengetahui dan melakukan penelitian di suatu rumah sakit. Peneliti merencanakan untuk melakukan penelitian dengan mengambil objek penelitian di Rumah Sakit Ibu dan Anak Bunda Aliyah Jakarta (RSIA Bunda Aliyah) yang berada dijalan Pahlawan Revolusi No. 100, Kelurahan Pondok Bambu, Kecamatan Duren Sawit Jakarta Timur. Rumah Sakit Ibu dan Anak Bunda Aliyah merupakan rumah sakit khusus dalam menyelenggarakan kesehatan terhadap permasalahan ibu dan anak.

Berdasarkan penelitian awal yang dilakukan oleh peneliti di IGD RSIA Bunda Aliyah terhadap informan yang bekerja di IGD RSIA Bunda Aliyah diperoleh data awal laporan waktu tanggap yang belum sesuai standar. Dari 700 pasien IGD pada bulan Juli tahun 2020, terdapat 89 pasien $(6,25 \%)$ yang waktu tanggapnya lebih dari 5 menit. Menurut informan hal ini disebabkan antara lain jumlah tenaga perawat yang kurang, hanya ada 12 orang tenaga perawat dari total 16 perawat yang dibutuhkan di IGD. Selain itu faktor lain yang diduga berpengaruh terhadap waktu tanggap di IGD RSIA Bunda Aliyah adalah masa kerja perawat di IGD dimana 7 dari 12 orang perawat memiliki masa kerja dibawah 1 tahun. Hal ini mungkin mempengaruhi keahlian perawat yang berdampak pada waktu tanggap yang lebih dari 5 menit dalam menangani pasien IGD. Kemudian ada faktor lain yang menghambat waktu pemeriksaan pasien yaitu pengantar pasien yang kurang mengetahui kondisi pasien sehingga pemeriksaan memerlukan analisa yg lebih mendalam.

Menurut sumber informan didapat juga bahwa beberapa dokter jaga IGD memerlukan waktu penanganan pasien lebih dari 5 menit, diduga dokter jaga belum cukup memiliki pengalaman atau skill dalam penanganan berbagai macam jenis kasus gawat darurat. Selain itu turn over dokter jaga yang tinggi juga diduga mempengaruhi waktu tanggap dimana rata-rata lama bekerja dokter jaga tersebut sebagian hanya selama 6 bulan. Rata-rata dokter jaga IGD tersebut adalah baru lulus dokter profesi (fresh graduate) dan menurut informan, faktor penggajian juga menjadi salah satu pertimbangan tingginya turn over dokter jaga di IGD RSIA Bunda Aliyah.

Dari penelitian awal yang dilakukan oleh peneliti, maka faktor waktu tanggap 
penanganan pasien di IGD merupakan hal yang sangat penting yang harus dipenuhi oleh setiap orang yang bekerja di IGD Rumah Sakit, dimana ketentuannya sudah diatur dalam Kepmenkes 129 tahun 2008. Jika waktu tanggap tersebut tidak dapat dipenuhi oleh IGD rumah sakit, maka akan menimbulkan permasalahan bagi layanan rumah sakit khususnya kepada pasien IGD yang akan berdampak juga kepada kualitas pelayanan rumah sakit.

\section{TUJUAN PENELITIAN}

Menganalisis pengaruh pengantar pasien, kondisi pasien, dan beban kerja tenaga kesehatan terhadap waktu tanggap di IGD Rumah Sakit Ibu dan Anak Bunda Aliyah Jakarta tahun 2020 melalui metode pendekatan masalah.

\section{METODE PENELITIAN}

Penelitian kuantitatif dengan studi potong lintang, dengan sampel sebanyak 30 responden. Penelitian ini dilakukan di IGD RSIA Bunda Aliyah Jakarta pada bulan Juli 2020 sampai bulan Agustus 2020. Sumber penelitian ini menggunakan data primer yaitu hasil pengamatan waktu proses pasien datang ke IGD sampai pasien dilayani dictatat dengan alat stopwatch dan data sekunder berupa data rumah sakit, dokumen rumah sakit di IGD, SOP di IGD, daftar sarana prasarana yang ada id IGD dan jumlah serta kualifikasi sumber daya manusia di IGDAnalisa kuantitatif digunakan untuk menganalisis perhitungan waktu tanggap pasien di IGD dengan faktor-faktor yang mempengaruhinya antara lain pengantar pasien, kondisi pasien dan beban kerja tenaga kesehatan.

\section{HASIL DAN PEMBAHASAN}

\section{Analisis Univariat}

Tabel 1

Frekuensi Distribusi Faktor Demografi

Karakteristik Jumlah (n) Persentase (\%)

\begin{tabular}{lcc}
\hline Karakteristik & Jumlah (n) & Persentase (\%) \\
\hline Umur & & \\
$\quad<35$ tahun & 25 & 83 \\
$\quad>35$ tahun & 5 & 17 \\
Jenis Kelamin & & \\
$\quad$ Laki-laki & 3 & 11,1 \\
$\quad$ Perempuan & 27 & 88,9 \\
Pendidikan & & \\
$\quad$ S1 & 12 & 40 \\
$\quad$ Keperawatan & 18 & 60 \\
$\quad$ Dokter & & \\
Masa Kerja & & \\
$\quad<3$ tahun & 21 & 70 \\
$\quad>3$ tahun & 9 & 30 \\
Status Perkawinan & & \\
$\quad$ Kawin & 12 & 40 \\
$\quad$ Tidak Kawin & 18 & 60 \\
\hline
\end{tabular}

Berdasarkan tabel 1 diatas diketahui bahwa mayoritas umur responden adalah < 35 tahun sebanyak $83 \%$. Berdasarkan jenis kelamin sebagian besar responden berjenis kelamin perempuan yaitu $88,9 \%$. Kemudian dilihat dari tingkat pendidikannya diketahui sebagian besar responden pendidikan terakhirnya Kedokteran yaitu $60 \%$. Diketahui juga sebagian besar masa kerja responden < 3 tahun yaitu $70 \%$. Dan siketahui bahwa mayoritas responden tidak kawin yaitu $60 \%$.

Tabel 2

Frekuensi Distribusi Variabel

\begin{tabular}{|l|c|c|}
\hline \multicolumn{1}{|c|}{ Variabel } & Jumlah (n) & Persentase (\%) \\
\hline Pengantar Pasien & & \\
Tidak Ada & 10 & 33,3 \\
Ada & 20 & 66,7 \\
\hline Kondisi Pasien & & \\
Kurang Baik & 14 & 46,7 \\
Baik & 16 & 53,3 \\
\hline Beban Kerja & 13 & \\
Rendah & 17 & 43,3 \\
Tinggi & & 56,7 \\
\hline Waktu Tanggap & 16 & 53,3 \\
Rendah & 14 & 46,7 \\
Tinggi & 30 & 100 \\
\hline Total & & \\
\hline
\end{tabular}


Berdasarkan tabel 2 di atas diketahui ada pengantar pasien ke instalasi gawat darurat RSIA Bunda Aliyah Jakarta sebanyak $66,7 \%$. Mayoritas beban kerja tenaga kesehatan tinggi di instalasi gawat darurat RSIA Bunda Aliyah yaitu 56,7\%. Dan diketahui kondisi pasien mayoritas Baik sebesar 53,3\%, dan waktu tanggap di instalasi gawat darurat RSIA Bunda Aliyah Jakarta mayoritas rendah yaitu $53,3 \%$.

\section{Analisis Bivariat}

Hasil analisis hubungan antara kinerja dengan komitmen organisasi, budaya organisasi, dan kompensasi sebagai berikut : faktor yang berhubungan bermakna ( $p \leq 0.05$ ) terhadap kinerja adalah dengan komitmen organisasi, budaya organisasi, dan kompensasi.

Tabel 2

Hubungan Variabel dengan Kinerja Karyawan di RS

\section{a. Tidak Ada Pengaruh antara Pengantar Pasien terhadap Waktu Tanggap}

Hasil uji pengaruh antara antara Pengantar Pasien terhadap Waktu Tanggap diperoleh nilai dengan taraf signifikansinya 0,260 (lebih besar dari 0,05). Dengan demikian dapat dikatakan bahwa pengantar pasien tidak berpengaruh signifikan terhadap waktu tanggap.

Pendampingan/pengantar adalah proses perjumpaan pertolongan antara pendamping dan orang yang didampingi. Perjumpaan itu bertujuan untuk menolong orang yang didampingi agar dapat menghayati keberadaannya dan mengalami pengalamannya secara penuh dan utuh, sehingga dapat menggunakan sumber-sumber yang tersedia untuk berubah, bertumbuh, dan berfungsi penuh secara fisik mental, spiritual dan sosial (Wiryasaputra, 2006). Pendampingan terutama mengacu pada semangat, tindakan memedulikan dan mendampingi secara generik.

\begin{tabular}{|c|c|c|c|c|c|c|c|c|c|}
\hline \multirow[b]{3}{*}{ NO } & & & \multicolumn{4}{|c|}{ Waktu Tanggap } & \multirow{3}{*}{$\begin{array}{c}P \\
\text { value }\end{array}$} & \multicolumn{2}{|c|}{ OR95\%Cl } \\
\hline & \multirow{2}{*}{\multicolumn{2}{|c|}{ VARIABEL }} & \multicolumn{2}{|c|}{ Lambat } & \multicolumn{2}{|c|}{ Cepat } & & \multirow[b]{2}{*}{ lower } & \multirow[b]{2}{*}{ upper } \\
\hline & & & $\mathrm{N}$ & $\%$ & $n$ & $\%$ & & & \\
\hline \multirow[b]{3}{*}{1} & \multirow{3}{*}{$\begin{array}{l}\text { Pengantar } \\
\text { Pasien }\end{array}$} & Tidak & & & & & \multirow[b]{3}{*}{0,260} & \multirow{3}{*}{\multicolumn{2}{|c|}{$\begin{array}{c}2,852(0,568- \\
14,326)\end{array}$}} \\
\hline & & Ada & 7 & 43,8 & 3 & 21,4 & & & \\
\hline & & Ada & 9 & 56,3 & 11 & 78,6 & & & \\
\hline \multirow[b]{2}{*}{2} & \multirow{2}{*}{$\begin{array}{l}\text { Kondisi } \\
\text { Pasien }\end{array}$} & $\begin{array}{l}\text { Tidak } \\
\text { Gawat }\end{array}$ & 11 & 68,8 & 3 & 21,4 & \multirow[b]{2}{*}{0,014} & \multirow{2}{*}{\multicolumn{2}{|c|}{$\begin{array}{c}8,067(1,538- \\
42,318)\end{array}$}} \\
\hline & & Gawat & 5 & 31,3 & 11 & 78,6 & & & \\
\hline \multirow{3}{*}{3} & \multirow{3}{*}{ Beban Kerja } & Rendah & 10 & 62,5 & 3 & 21,4 & \multirow{3}{*}{0,033} & \multirow{2}{*}{\multicolumn{2}{|c|}{$\begin{array}{c}6,111(1,198- \\
31,164)\end{array}$}} \\
\hline & & Tinggi & 6 & 37,5 & 11 & 78,6 & & & \\
\hline & & & 16 & 100 & 14 & 100 & & & \\
\hline
\end{tabular}

\section{Analisis Multivariat}

Tabel 3

Multivariat

R square Nagelkerke

$0,249=24.9 \%$

$0.284=28,4 \%$
Biasanya, pendampingan mengacu pada hubungan bantuan psikologis secara informal sebagai lawan pada hubungan bantuan psikologis secara formal dan profesional. Pendampingan bisa dihubungkan dengan sikap dan tindakan yang dilakukan oleh orang yang 
tidak berprofesi bantuan psikologis secara penuh waktu, namun menginginkan layanannya lebih manusiawi (Wiryasaputra, 2006)

Tugas utama seorang pendamping adalah membantu orang yang didampingi untuk mengalami pengalamannya secara penuh dan utuh. Dengan demikian pendamping membantu orang yang didampingi merayakan suka dan duka kehidupan secara penuh dan utuh (Wiryasaputra, 2006). Pendamping tidak hanya melakukan tindakan penyembuhan, melainkan juga pencegahan, peningkatan, pemulihan, dan pemberdayaan. Sebuah layanan yang bersifat komprehensif artinya pendamping dapat membantu menghilangkan rasa susah, marah, terkejut, bingung, tertekan dan putus asa. Kemudian pendamping dapat menolong klien menjadi pendamping bagi dirinya pada masa depan atau menolong orang disekitarnya. Pendamping juga menciptakan perubahan bagi klien dan lingkungannya (Wiryasaputra, 2006).

Hasil penelitian ini senada dengan hasil penelitian yang dilakukan Ines Mariane tahun 2016 yang berjudul "Faktor-Faktor Yang Mempengaruhi Waktu Tanggap Pasien Di Instalasi Gawat Darurat Rumah Sakit "X" Tahun 2016" memberikan hasil faktor-faktor yang tidak berhubungan dengan waktu tanggap adalah pengantar pasien, sarana prasarana, kehadiran dokter, kebijakan surat rujukan.

International Jurnal, Ciufo D, Hader R, and Holly C tahun 2011 mengenai " $A$ comprehensive systematic review of visitation models in emergency units within the context of patient- and family-centred care", pada penelitian ini pengantar atau pendamping pasien merupakan sesuatu yang berbeda untuk pasien, keluarga, dan perawat. Pasien memiliki kebutuhan untuk kenyamanan dan dukungan. Selain itu pengantar bermanfaat bagi pasien dan keluarga. Pasien dan keluarga menginginkan informasi yang diberikan pada mereka dapat dimengerti dan mengetahui prognosis tentang pasien.

\section{b. Ada Pengaruh yang Signifikan antara Kondisi Pasien terhadap Waktu Tanggap}

http://ejournal.urindo.ac.id/index.php/MARSI
Hasil uji pengaruh secara parsial antara Kondisi Pasien terhadap waktu tanggap diperoleh nilai dengan taraf signifikansinya $0,014(<0,05)$. Dengan demikian dapat dikatakan bahwa kondisi pasien berpengaruh positif dan signifikan terhadap waktu tanggap

Di Victoria, Australia prioritas response time berdasarkan protokol triage yaitu Medical Priority Dispatch System (MPDS). MPDS adalah pengelompokkan menurut keluhan utama, tingkat keparahan keluhan, dan prioritas pengiriman. Keluhan utama dikelompokkan ke dalam lebih dari 30 prasyarat medis utama mulai dari nyeri dada sampai masalah mata. Tingkat keparahan keluhan ditentukan saat ditanyai, dan didefinisikan menggunakan lima kategori yang mulai dari tingkat Alpha (paling tidak serius) sampai Echo (mengancam nyawa). Tingkat keparahan diberi label "Code 1" untuk kasus kritis, kasus kritis tapi tidak darurat diberi label "Code 2", tidak gawat dan tidak darurat diberi label "Code 3". Kasus "Priority Zero" digunakan untuk subklasifikasi kasus Code 1 dimana pasien berada dalam ancaman langsung seperti kasus jantung dan pernapasan (Nehme et al. 2016).

Kata triage beasal dari bahasa Prancis "Trier" yang berarti membagi dalam tiga kelompok (Kartikawati. N. 2013). Sistem ini digunakan dalam medan pertempuran dan bila terjadi bencana untuk menentukan prioritas penanganan. Triage mulai digunakan di IGD pada akhir tahun 1950, karena peningkatan jumlah kunjungan dan menyebabkan waktu tunggu serta keterlambatan penanganan kasus yang gawat.

Dalam dunia medis triage adalah proses pengambilan keputusan yang kompleks dalam rangka menentukan pasien mana yang berisiko meninggal, berisiko mengalami kecacatan, atau berisiko memburuk keadaan klinisnya apabila tidak mendapatkan penanganan medis segera, dan pasien mana yang dapat dengan aman menunggu. Berdasarkan definisi ini, proses triage diharapkan mampu menentukan kondisi pasien yang memang gawat darurat, dan 
kondisi yang berisiko gawat darurat (Habib et al. 2016).

Hasil penelitian ini sejalan dengan penelitian yang dilakukan oleh Rima Wahyu Aprianti M. Naser tahun 2017 yang menyatakan bahwa terdapat hubungan kondisi pasien dengan response time perawat dengan $p=$ 0,005

Dalam studi Crossectional yang dilakukan Andersson, A.K., M. Omberg, dan M. Svedlund (2017) dalam jurnal "Factors Related To Nurse Respond Time On Handling of Emergency Patient" membagi faktor yang memengaruhi response time menjadi dua yaitu faktor internal dan ekstarnal. Yang termasuk faktor internal meliputi keterampilan perawat dan kapasitas pribadi, sedangkan faktor eksternal meliputi kondisi klinis pasien dan riwayat klinis pasien

Hal ini didukung oleh laporan dari Canadian Institute for Health Information (ClHI) pada tahun 2005 yang menunjukkan bahwa tidak semua faktor-faktor seperti keberagaman lama rawat di IGD terkait waktu-waktu tertentu pada hari yang sama, demikian juga jumlah kunjungan IGD dan tingkat keparahan kondisi pasien, memiliki peranan dalam memperpanjang waktu tunggu pasien terhadap dokter yang menanganinya pada saat registrasi dan triase.

\section{c. Ada Pengaruh yang Signifikan antara Beban Kerja terhadap Waktu Tanggap}

Hasil uji pengaruh secara parsial antara beban kerja terhadap waktu tanggap diperoleh nilai dengan taraf signifikansinya 0,029 $(<0,05)$. Dengan demikian dapat dikatakan bahwa beban kerja berpengaruh positif dan signifikan terhadap waktu tanggap

Menurut UU Kesehatan No.36 Tahun

2009 menyatakan bahwa beban kerja merupakan hasil kali antara jumlah pekerjaan dengan waktu dan besaran pekerjaan yang harus dipikul oleh suatu jabatan/unit organisasi. Menurut Everly dkk (dalam Putra \& Prihatsanti, 2016) mengatakan bahwa beban kerja adalah

http://ejournal.urindo.ac.id/index.php/MARSI keadaan ketika pekerja dihadapkan pada tugas yang harus diselesaikan tepat waktu.

Menurut Riggio (dalam Purbaningrat \& Surya, 2015) menyatakan beban kerja adalah tugas-tugas pekerjaan yang menjadi sumber stress seperti pekerjaan mengharuskan bekerja dengan cepat, menghasilkan konsentrasi dari stress kerja, menurut Marquis dan Houston (2010) beban kerja perawat adalah seluruh kegiatan atau aktivitas yang dilakukan oleh seorang perawat selama bertugas di suatu unit pelayanan keperawatan. Workload atau beban kerja diartikan sebagai patient days yang merujuk pada jumlah prosedur, pemeriksaan kunjungan (visite) pada klien.

Hasil penelitian tentang beban kerja di bagian pelayanan intensif Norwegia didapatkan bahwa score aktifitas perawat $75-90 \%$ per perawat (Satfseth, 2011).

Adapun hasil penelitian yang dilakukan oleh Widodo dan Pratiwi (2008), menyatakan bahwa beban kerja perawat IGD RSU Pandan Arang Boyolali dalam kategori tinggi. Waktu tanggap perawat gawat darurat menurut persepsi pasien di IGD RSU Pandan Arang Boyolali dalam kategori yang sama yaitu cepat dan lambat, Ada hubungan antara beban kerja fisik dengan waktu tanggap perawat gawat darurat.

Pada penelitian yang dilakukan oleh widodo dan pratiwi (2008) juga menyebutkan bahwa ada hubungan beban kerja sosial, psikologis, dan total dengan waktu tanggap. Hal ini menunjukan bahwa dapat dipertimbangkan beberapa faktor lain yang mempengaruhi response time perawat. Seperti, lama kerja perawat, usia, tidak seimbangnya jumlah perawat dengan pasien, dll.

Dalam studi observasi yang dilakukan oleh Potter \& Peryy tahun 2018 dengan judul "The Relationship Between Workload and Respon Time in Emergency Department" menyatakan beban kerja berhubungan dengan respon yang diberikan oleh perawat.

Jadi beban kerja dapat diartikan kemampuan dari manusia dalam menerima pekerjaan harus sesuai dan seimbang baik 
terhadap kemampuan fisik, kemampuan kognisi maupun keterbatasan manusia yang menerima dari setiap beban kerja tersebut tanpa membahayakan dirinya sendiri dan masyarakat di sekelilingnya terutama pasien yang berada di Rumah Sakit, sehingga perlu dilakukan penyerasian antara beban kerja, kapasitas kerja dan lingkungan kerja utuk memperoleh produktivitas kerja yang optimal

Beban kerja adalah besaran pekerjaan yang harus dipikul oleh suatu jabatan/unit organisasi dan merupakan hasil kali antara volume kerja dan norma waktu. Pengertian beban kerja adalah sekumpulan atau sejumlah kegiatan yang harus diselesaikan oleh suatu unit organisasi atau pemegang jabatan dalam jangka waktu tertentu. Pengukuran beban kerja diartikan sebagai suatu teknik untuk mendapatkan informasi tentang efisiensi dan efektivitas kerja suatu unit organisasi, atau pemegang jabatan yang dilakukan secara sistematis dengan menggunakan teknik analisis jabatan, teknik analisis beban kerja atau teknik manajemen lainnya. Lebih lanjut dikemukakan pula, bahwa pengukuran beban kerja merupakan salah satu teknik manajemen untuk mendapatkan informasi jabatan, melalui proses penelitian dan pengkajian yang dilakukan secara analisis. Informasi jabatan tersebut dimaksudkan agar dapat digunakan sebagai alat untuk menyempurnakan aparatur baik di bidang kelembagaan, ketatalaksanaan, dan sumber daya manusia

\section{KESIMPULAN}

Berdasarkan hasil penelitian dan pembahasannya, maka peneliti dapat menarik suatu kesimpulan beberapa hal sebagai berikut:

1. Response time tenaga kesehatan di IGD RSIA Bunda Aliyah 53\% dalam kategori kurang baik(>5 menit)

2. Beban kerja tenaga kesehatan di IGD RSIA Bunda Aliyah 57\% dalam kategori Tinggi

3. Kondisi pasien di IGD RS Bunda Aliyah 53\% dalam kategori Baik (Tidak Gawat darurat)
4. Tidak terdapat pengaruh antara pengantar pasien terhadap waktu tanggap diperoleh nilai dengan taraf signifikansinya 0,260 (lebih besar dari 0,05)

5. Terdapat pengaruh secara parsial antara Kondisi Pasien terhadap waktu tanggap diperoleh nilai dengan taraf signifikansinya $0,014(<0,05)$

6. Terdapat pengaruh secara parsial antara beban kerja terhadap waktu tanggap diperoleh nilai dengan taraf signifikansinya $0,029(<0,05)$

7. Kondisi pasien dan beban kerja dapat menjelaskan 28,4 \% dari variabel waktu tanggap. Dan terdapat $(100,0 \%-28,4 \%=$ $71,6 \%) 71,6 \%$ variabel atau faktor lain yang tidak diteliti dapat menjelaskan variabel waktu tanggap di Rumah Sakit antara lain lama kerja, pengetahuan, kompetensi tenaga kesehatan, stress kerja dan lingkungan kerja.

\section{SARAN}

1. Mekanisme waktu tanggap juga dapat mengurangi beban pembiayaan. Kecepatan dan ketepatan pertolongan yang diberikan pada pasien yang memerlukan standar sesuai dengan kompetensi dan kemampuannya sehingga dapat menjamin suatu penanganan gawat darurat dengan waktu tanggap yang cepat dan penanganan yang tepat. Hal ini dapat dicapai dengan meningkatkan sarana, prasarana, sumber daya manusia dan manajemen rumah sakit sesuai standar

2. Pada saat pandemic ini di Rumah sakit, triase sudah dilakukan di Instalasi Gawat Darurat (IGD). Pasien datang dengan berbagai kondisi medis, begitu juga dengan kondisi pasien yang akan dirawat inap baik pasien COVID-19 maupun non COVID-19 yang dapat berada dalam kondisi gawat darurat. Saran dari peneliti Gugus tugas emergensi harus diaktifkan dengan rantai komando, peran dan tanggung jawab yang jelas, memiliki wadah untuk berbagi informasi yang dapat 
diandalkan serta dengan pendekatan proaktif.

3. Tim IGD Rumah Sakit harus disiapkan untuk menangani berbagai kondisi emergensi dengan segera walaupun dalam situasi pandemi ini, beberapa setting emergensi membutuhkan penyesuaian salah satu contohnya adalah praktik resusitasi terhdap pasien true emergency yg terkonfirmasi positif Covid 19.

4. Manajemen dan tim dapat mengatasi tantangan yang dihadapi adalah bagaimana memastikan pasien dengan atau tanpa COVID-19 yang mengalami keadaan gawat darurat seperti henti jantung mendapatkan kesempatan untuk selamat tanpa membahayakan keselamatan penolong yang tentunya akan dibutuhkan untuk merawat pasien - pasien berikutnyaDi rumah sakit, triase dilakukan

5. Dilakukan rapat rapat rutin untuk evaluasi peananganan pasien IGD 1 bulan sekali bersama bagian unit pelayanan lain

6. Diharapkan bagi pihak mutu RS selalu memantau, mengevaluasi waktu tanggap pelayanan pasien terutama yang true emergency di instalasi gawat darurat supaya waktu tanggapnya selalu sesuai standar pelayanan minimal baik standar nasional maupun internasional.

7. Manajemen hendaknya memberikan pelatihan pelatihan berkala kepada perawat dan dokter IGD, seperti simulasi penanganan pasien gawat darurat. Dan mengikuti kursus BTLS, ATLS, ACLS ulang

8. Diharapkan bagi pihak mutu RS selalu memantau, mengevaluasi secara berkala waktu tanggap pelayanan pasien terutama yang true emergency di instalasi gawat darurat supaya waktu tanggapnya selalu sesuai standar pelayanan minimal IGD secara nasional

9. Variabel karakteristik pasien dan variable pengetahuan, keterampilan dan pengalaman petugas kesehatan diperlukan untuk diteliti lebih lanjut.

\section{DAFTAR PUSTAKA}

1. Departemen Kesehatan Republik Indonesia, (2006). Sistem Penanggulangan Gawat Darurat Terpadu. Jakarta: Departemen Kesehatan Republik Indonesia

2. Fetter, Robert, John D Thompson, (1966). Patient waiting time and doctor's idle time in the out patient setting.

3. Hannibal P, (2000) Studi faktor-faktor yang berhubungan dengan waktu tunggu UGD di Rumah Sakit Bhakti Yudha Tahun 2000. Fakultas Kesehatan Masyarakat Universitas Indonesia. Depok.

4. Herkunto, (2008) Aspek Medikolegal Pelayanan Gawat Darurat. Bagian IImu Kedokteran Forensik dan Medikolegal Fakultas Kedokteran Universitas Indonesia.

5. John D, (2015) Emergency Service Response Time. VAGO. Melbourne, Austalia

6. Keputusan Menteri Kesehatan Republik Indonesia, (2009). Nomor 856 Tahun 2009. Standar Instalasi Gawat Darurat (IGD) Rumah Sakit.

7. Keputusan Menteri Kesehatan Republik Indonesia, (2008). Nomor 129 Tahun 2008. Standar Pelayanan Minimal Rumah Sakit.

Nailatul F,dkk (2013) Faktor-faktor yang berhubungan dengan waktu tanggap pada pelayanan kasus kecelakaan lalu lintas di IGD RSUP DR. M. Djamil Padang Tahun 2013. Fakultas Kedokteran Universitas Andalas. Padang.

8. Mahyawati. (2015) Hubungan Kegawatdaruratan Pasien dengan Waktu Tanggap Perawat di IGD RS PKU Muhammadiyah Yogjakarta. Yogyakarta 
9. Nazir M, (2005), Metode Penelitian, Bogor: Ghalia Indonesia.

10. Noor, (2009). Faktor-Faktor Yang Mempengaruhi Response Time Pada Penanganan Pasien Instalasi Gawat Darurat RSUP Persahabatan. Jakarta

11. Notoatmodjo S.,(2010) Metodelogi Penelitian Kesehatan, Jakarta: Rineka Cipta.

12. Oliviani P, dkk. (2014). Faktor-faktor yang mempengaruhi waktu tunggu pasien di Instalasi Gawat Darurat Medik RSUP Prof. DR. R.D Kandou Manado. Universitas Sam Ratulangi Manado.

13. Oscar M,Miquel, Jose. (1999) Relative effects of internal and external factors on emergency department efficiency. Bersumber: www.google.com : https://www.bmj.com/rapidresponse/2011/10/28/relative-effectsinternal-and-external-factors-emergencydepartment-effici

14. Peraturan Menteri Kesehatan Republik Indonesia, (2014) Nomor 56 Tahun 2014. Klasifikasi dan Perizinan Rumah Sakit

15. Rumah Sakit Infeksi Sulianti Saroso. 2013. Laporan waktu tanggap pasien di IGD.

16. Sabriyanti W, dkk, (2012). Faktor-Faktor Yang Berhubungan Dengan Ketepatan Waktu Tanggap Penanganan Kasus Pada Response Time I Di Instalasi Gawat Darurat Bedah Dan Non-Bedah RSUP DR.Wahidi Sudirohusodo, Makasar: Jurnal Universitas Hasanudin, Dalam http:// pasca.unhas.ac.id.
17. Sanchez, dll, (2002) Analysis of patient flow in emergency department and the effect of an extensive reorganization. Bersumber: www.google.com:http://www.ncbi.nIm.n ih.gov/pmc/articles/PMC1726061/pdf/v0 20p00143.pdf

18. Saryono. (2011) Metodelogi Penelitian Kesehatan. Mitra. Yogyakarta. Sugiono, (2007) Metode Penelitian Kuantitatif, Kualitatif dan R\&D. Penerbit: Alfabeta. Bandung.

19. Sutanto, (2006). Statistik Kesehatan. Rajawali Pers: Depok.

20. The Australian Council On Healthcare Standards (1998). Clinical indicators a user's manual: Emergency medicine indicators. The Australian College for Emergency Medicine.

21. Wijono D, (1999) Manajemen mutu pelayanan kesehatan. Surabaya: Airlangga.

22. World Health Organization, (2013).Emergency Response Framework.

23. Yoon P, Steiner, Reinhart, (2003) Analysis of factors influencing length of stay in the emergency department. Bersumber: www.google.com: http://www.ncbi.nlm.nih.gov/pubmed/1 747277 
Jurnal Manajemen Dan Administrasi Rumah Sakit Indonesia ISSN: 2865-6583

Vol.5 No 1, April 2021

P-

ISSN: 2865-6298 